\title{
On sourcing obsidian assemblages from the Mediterranean area: analytical strategies for their exhaustive geochemical characterisation is
}

\author{
Marie Orange ${ }^{\mathrm{a}}$, François-Xavier Le Bourdonnec ${ }^{\mathrm{b}, *}$, Ludovic Bellot-Gurlet ${ }^{\mathrm{c}}$, Carlo Lugliè ${ }^{\mathrm{d}}$, Stéphan Dubernet ${ }^{\mathrm{b}}$, \\ Céline Bressy-Leandri ${ }^{\mathrm{e}}$, Anja Scheffers ${ }^{\mathrm{a}}$, Renaud Joannes-Boyau ${ }^{\mathrm{a}}$ \\ a Southern Cross GeoScience, Southern Cross University, Military Road, PO Box 157, Lismore, NSW 2480, Australia \\ b IRAMAT-CRP2A, UMR 5060 CNRS-Université Bordeaux Montaigne, Maison de l'Archéologie, Esplanade des Antilles, 33607 Pessac, France \\ ' Sorbonne Universités, UPMC Université Paris 6, MONARIS 'de la Molécule aux Nano-objets: Réactivité, Interactions et Spectroscopies', UMR 8233, UPMC-CNRS, 75005 Paris, France \\ ' LASP, Dipartimento di Storia, Beni Culturali e Territorio, Università di Cagliari, 09124 Cagliari, Italy \\ e TRACES, UMR 5608, Université de Toulouse Jean-Jaurès, CNRS, MCC; Ministère de la Culture et de la Communication, DRAC de Corse, 20704 Ajaccio, France
}

\section{A R T I C L E I N F O}

\section{Article history:}

Received 5 February 2016

Received in revised form 23 May 2016

Accepted 1 June 2016

Available online 14 June 2016

\section{Keywords:}

Obsidian sourcing

Analytical strategy

Archaeology

Western Mediterranean

Aegean

\begin{abstract}
A B S T R A C T
This paper presents an overview of the work conducted by our research group in the Mediterranean area. Initiated in the 1990s by the late Gerrard Poupeau, our research relies on international and multidisciplinary collaborations to endeavour archaeological and anthropological issues linked to the diffusion and consumption of the obsidian raw material during the Neolithic period. Our line of action is to develop flexibly unique analytical strategies, tailored to each obsidian assemblage considered for a sourcing study. Drawing its strength from the complementarity of the methods available within our group, i.e. visual characterisation, SEM-EDS, ED-XRF, pXRF, PIXE, and LA-ICP-MS, this approach allows for the exhaustive and non-destructive analysis of those assemblages, thus optimising the potential of sourcing studies. Working hand in hand with archaeologists, the results are closely integrated to the information brought by the typological and technological characteristics of the artefacts, in the aim to reconstruct an overview of the obsidian economy at site level, but also to replace it in a broader regional and supra-regional - context.
\end{abstract}

(c) 2016 Elsevier Ltd. All rights reserved.

\section{Introduction}

The geochemical sourcing of obsidian artefacts has long been a successful way to improve our understanding of the socioeconomic context of past populations (Renfrew, 1969; Clark, 1981; Elam, 1993; Glascock et al., 1998). Emerging in the 1960s with the work of Cann and Renfrew (1964), Renfrew et al. (1966, 1968, i.a.), obsidian sourcing studies in archaeology have constantly been expanding over the last decades (Williams-Thorpe, 1995; Tykot, 1996; Freund, 2013, Fig. 1; Carter, 2014, Fig. 1). Such a thriving and popular field however requires constant monitoring to assess where the discipline as a whole is heading. Victim of its success, obsidian sourcing was indeed sometimes used without real consideration for the underlying archaeological issue. This type of study, generally focusing on the development of a particular

\footnotetext{
it This article is dedicated to the memory of Dr Gérard Poupeau.

* Corresponding author.

E-mail addresses: m.orange.10@student.scu.edu.au (M. Orange),

Francois-Xavier.Le-Bourdonnec@u-bordeaux-montaigne.fr (F.-X. Le Bourdonnec), ludovic.bellot-gurlet@upmc.fr (L. Bellot-Gurlet), luglie@unica.it (C. Lugliè), Stephan.Dubernet@u-bordeaux-montaigne.fr (S. Dubernet), celine.leandri@culture.gouv.fr (C. Bressy-Leandri),Anja.Scheffers@scu.edu.au (A. Scheffers), renaud.joannes-boyau@scu.edu.au (R. Joannes-Boyau).
}

analytical method or protocol, likely resulted from the constant search for an 'ideal' and 'universal' sourcing technique (Francaviglia, 1984) that would supersede all the others. While the development of efficient and reliable methods and protocols is certainly essential, this trend not only led to the multiplication of the techniques applied to the obsidian material but, consequently, to the proliferation of heterogeneous and thus hardly comparable - sourcing data. This 'idealistic' methodological quest was later given less importance, to focus on the instrumentation that was readily available to the researchers working in the field, and to find new - preferably non-destructive - ways to apply them to obsidian geochemical characterisation (Gratuze et al., 1993; Davis, 1994; Acquafredda et al., 1999; De Francesco et al., 2008, 2011; Poupeau et al., 2010; Forster and Grave, 2012; Frahm, 2012a; Le Bourdonnec et al., 2005, 2006, 2014, inter alia). This ‘switch' eventually brought the attention back to the essence of obsidian geochemical sourcing itself: providing information to resolve the archaeological problem(s) associated with each specific assemblage. Following this reasoning, the analysis is once again regarded as a means to an end (Carter, 2014, p. 23), i.e. bringing information to the archaeological context, and not as the end itself (see e.g. discussion in Freund, 2013, p. 786). Finally, it implies that the assemblage, depending on its characteristics, dictates the choice of the analytical method(s), and not the 


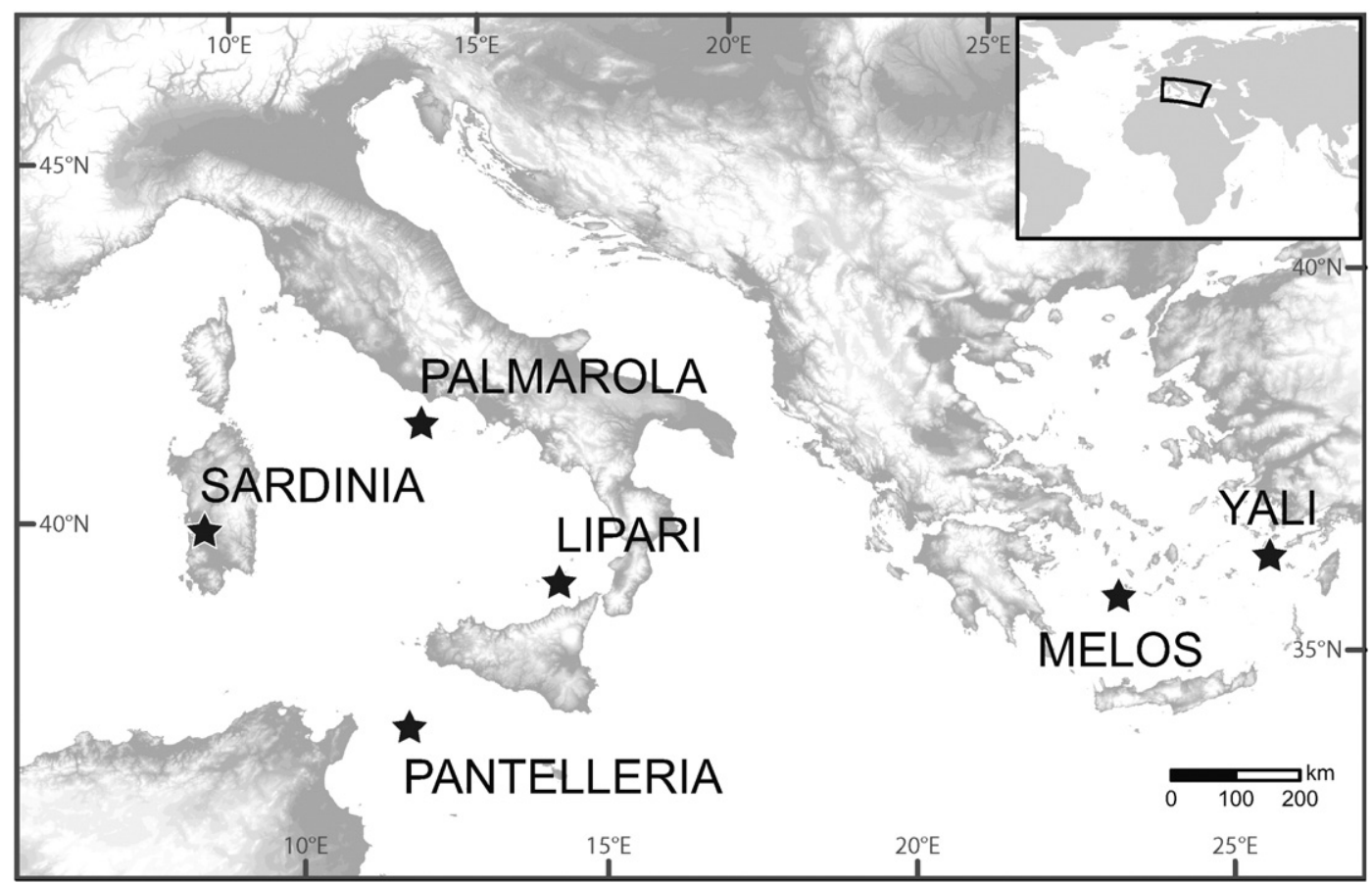

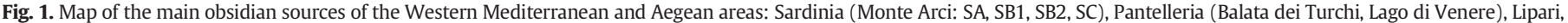
Palmarola, Melos, and Yali.

opposite. This is the principle of analytical strategy, formerly introduced by Poupeau et al. (2007, p. 82) and developed here.

\section{Geographical and archaeological framework}

The research presented here focuses on obsidian sourcing in the Mediterranean area, and more particularly on the Western Mediterranean (see e.g. Francaviglia, 1988; Tykot, 1997) and the Aegean (Carter and Contreras, 2012; Frahm et al., 2014 inter alia). Obsidian sources involved in this study are displayed on the map in Fig. 1: the Monte Arci in Sardinia (SA, SB1, SB2, SC), Pantelleria (Balata dei Turchi and Lago di Venere), Lipari, Palmarola, Melos, and Yali. The Near Eastern obsidian sources have been intentionally excluded, because their number and geochemical complexity put them outside the scope of this study.

Following former studies on Sardinian sites that used a source-based perspective (Le Bourdonnec et al., 2006; Lugliè et al., 2007, 2008a, 2008b, 2009, 2011; Lugliè, 2012), our research recently focused on collections from Neolithic sites in Corsica, Tunisia, Southern France, and Northern Italy (Bressy et al., 2008; Le Bourdonnec et al., 2010, 2011, 2014, 2015a; Lugliè et al., 2014). Through the Neolithic period, the island of Corsica and the North-western Mediterranean offer an interesting framework, since obsidian has a variable significance in the different lithic assemblages. This varies according to several characteristics: the chronological context, the number of artefacts and their typo-technological status, the relative distance between the sites and the obsidian sources, as well as the proportion of sources distribution in the raw matter supply. In solving archaeological problems of this complexity, a 'fluid' and adaptable approach to the studies of obsidian provenance is required, as quite specific archaeological questions can originate from either a handful or several hundred - if not thousands - of artefacts. Therefore, as a result of our flexible strategy comprising the possibility to use visual characterisation as well as a combination of analytical techniques, the sourcing of the whole collections can be achieved. This ultimately allows us to provide a sound interpretation to each underlying cultural and socio-economic issue.

For instance, over twenty years of provenance studies revealed that obsidian circulation in Neolithic Corsica (6th-4th millennium BC) was mainly dependent on procurement from the close island of Sardinia. More recently, even though for a long time the Monte Arci source has been considered exclusive, our analytical strategy detected the presence of a few obsidians from Palmarola in Corsica (Le Bourdonnec et al., 2014, 2015b). This suggests that an internal interaction took place inside the Northern Tyrrhenian basin, mainly during the first pioneer phase of the Western Mediterranean neolithisation, during the Early and Middle Neolithic. In addition, by the full Middle Neolithic (late 5th millennium $\mathrm{BC}$ ) the decrease in use of the dominant SB2 type from the Monte Arci source (Sardinia) in favour of a preferential and almost exclusive supply of SC and SA types (Tykot, 1996) has been explained in terms of an intervened large scale obsidian exploitation and production, in substitution of the older 'village-based' reduction system. This shift seems to be linked to the setup of specific spheres of influence in obsidian distribution from the sources of Lipari and Sardinia, so that Corsica was involved in the consistent and massive spread of the Monte Arci SA type obsidians and, in lesser amount, SC type obsidians towards the Northern Tyrrhenian and the Western Mediterranean (Lugliè, 2012). The significance and relevance of these obsidian exploitation patterns can only be assessed in the frame of a combined provenance and typo-technological study. Therefore, in order to obtain provenance results that could be discerningly discussed, this research selected collections fulfilling the following characteristics: (a) collections issued from documented archaeological contexts with fine stratigraphic/chronological resolution (often from quite recent and extensive excavations), (b) collections that will be typologically and technologically studied in order to discuss the chaîne opératoire, and (c) collections that could document a specific problem (e.g. diachronic trends of source exploitation, focus on a specific cultural phase, relation with other materials exchange networks in the frame of the increase of cultural interactions, etc.).

\section{Methods available within our research group}

A multitude of methods is now available for obsidian sourcing (see Poupeau et al., 2007, 2014; Shackley, 2011; Orange et al., in press). Our research group has access to quite a large panel of non-destructive and partially destructive methods, including: visual characterisation, 
Scanning-Electron Microscopy coupled to Energy Dispersive Spectroscopy [SEM-EDS], portable X-Ray Fluorescence Spectroscopy [pXRF], Energy Dispersive X-Ray Fluorescence Spectroscopy [ED-XRF], Ion Beam Analysis [IBA], and Laser Ablation Inductively Coupled Plasma Mass Spectrometry [LA-ICP-MS]. The advantages and limits of each method are considered here, along with their discrimination potential for the sources of the Mediterranean and Aegean areas.

\subsection{Visual characterisation}

The most readily accessible tool for obsidian characterisation is indubitably the human eye. Several macroscopic features can indeed help to distinguish different obsidian sources: transmittance (translucency, opacity), surface (texture, lustre), inclusions, flow banding (e.g. "difference in crystallinity or vesicularity"; Gonnermann and Manga, 2005, p. 136 , inter alia). Considered together, these characteristics can allow the visual sourcing of up to 70-97\% of an assemblage (Lugliè et al., 2007, 2008a; Milić et al., 2013), depending on the observer's experience to visually recognize the different obsidian sources of a given geographical area. The success of this approach also depends on the assemblage itself: artefacts that are too thick or too small to show their true coloration, presenting a cortex and/or substantial surface alterations are more difficult - if not impossible - to attribute. Yet the cortex itself, combined with other characteristics, can be a good (or even decisive) indicator of provenance, being the result of different degrees of alteration of various original surfaces. Low-cost and time-efficient (a trained eye can source an artefact in seconds), this method can nevertheless provide an efficient preliminary sorting/screening of an assemblage (Tykot and Ammerman, 1997). A combined visual and typo-technological analysis may also reduce the number of artefacts to be analysed, identifying elements coming out from the same parental unit. Furthermore, this can easily be conducted in-situ, thus permitting the sourcing of artefacts that cannot be transported to the laboratory (see e.g. Pierce, 2015).

\subsection{SEM-EDS}

Scanning Electron Microscopy coupled to Energy Dispersive Spectroscopy detector, or SEM-EDS, has been used in the field of obsidian sourcing for over 20 years (Acquafredda et al., 1996, 1999; Le Bourdonnec et al., 2006). Available in a large number of research facilities, it however requires the most invasive sample preparation in our panel of sourcing methods, i.e. the application of a carbon coating or the sampling of a small portion of the artefact (a fresh surface of only 1 to $2 \mathrm{~mm}^{2}$ is necessary for the analysis). Yet, this partially destructive protocol enables to produce results quickly with a very limited cost and allows - when conducted non-destructively with a carbon coating - to analyse artefacts ranging from a few micrometres to $\mathrm{ca} .15 \mathrm{~cm}$ (Acquafredda et al., 1999:321). At the IRAMAT-CRP2A, our research group has access to a JEOL JMS 6460 LV scanning electron microscope equipped with an energy dispersive spectrometer (Oxford Industries INCA X-sight). The user interface displays a live image of the sample, permitting to choose the flattest area for analysis, and to avoid surface alterations and inclusions where possible, which is also facilitated by the micrometre-sized electron beam. In addition, it allows for an instant monitoring of the results. The Western Mediterranean and Aegean sources are easily discriminated with this method, even when we only take into account the $\mathrm{CaO}, \mathrm{Al}_{2} \mathrm{O}_{3}$, and $\mathrm{SiO}_{2}$ contents (see Fig. 2). A discriminant analysis involving the $\mathrm{Na}_{2} \mathrm{O}, \mathrm{Al}_{2} \mathrm{O}_{3}, \mathrm{SiO}_{2}$, $\mathrm{K}_{2} \mathrm{O}$, and $\mathrm{CaO}$ contents after additive log-ratio (alr) transformation (see Aitchison, 1982; $\mathrm{Fe}_{2} \mathrm{O}_{3}$ contents as common divider) also clearly distinguishes the subtypes of the Monte Arci source (Fig. 3; see also Le Bourdonnec et al., 2006), despite what had been indicated in previous studies (Tykot, 1995). However, this method does not allow the measurement of trace elements, which is a limiting factor for more complex obsidian sourcing, e.g. in the Near East (see Poupeau et al., 2010). When

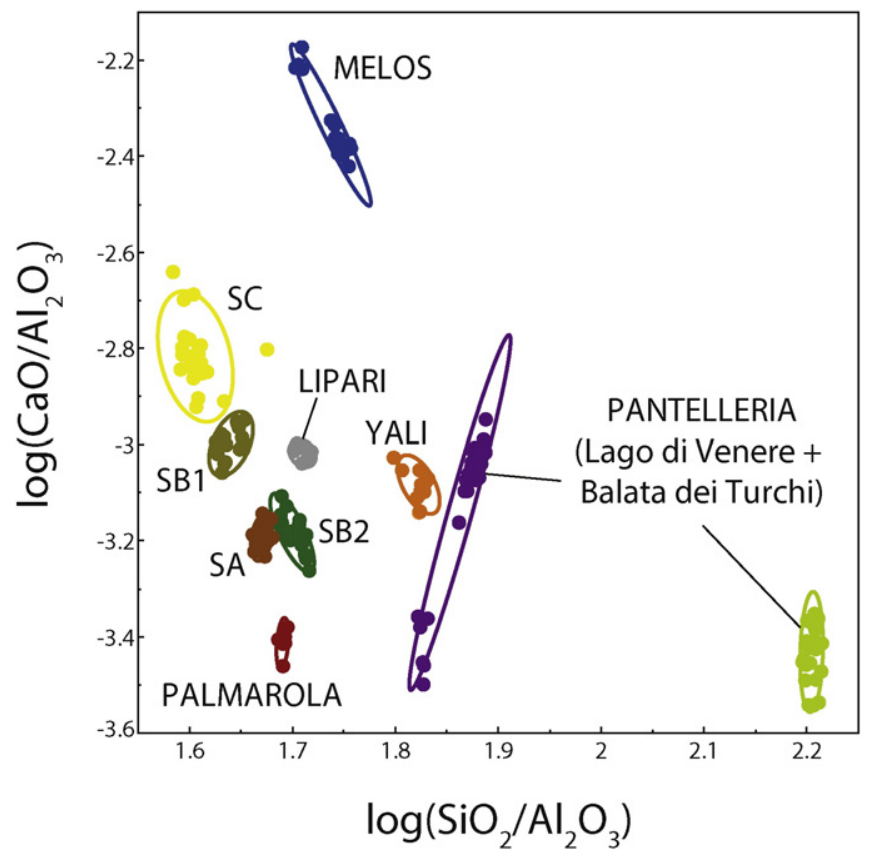

Fig. 2. Comparison of the $\log \left(\mathrm{SiO}_{2} / \mathrm{Al}_{2} \mathrm{O}_{3}\right)$ and $\log \left(\mathrm{CaO} / \mathrm{Al}_{2} \mathrm{O}_{3}\right)$ ratios obtained by SEM-EDS (IRAMAT-CRP2A) for 175 geological samples from the Mediterranean area (90\% density ellipses). Analyses conducted at the IRAMAT-CRP2A (France); see Le Bourdonnec et al., 2010.

applied to the archaeological samples (here, 223 artefacts from different Neolithic Corsican sites are taken into account), the attribution to each source is manifest (Fig. 4).

\subsection{Bench top ED-XRF}

With the SEM-EDS, Energy Dispersive X-Ray Fluorescence Spectroscopy is probably one of the most available analytical methods for obsidian sourcing. Its capacity to measure elements within the mid-Z X-ray region (mainly between $\mathrm{Ti}$ and $\mathrm{Nb}$; see Shackley, 2011; Glascock, 2011) allows to discriminate between the obsidian sources of many geographical areas, i.e. Near East (Carter and Shackley, 2007; Nadooshan et al., 2013; Orange et al., 2013), Northeast Asia (Hall and Kimura, 2002; Ikeya, 2014), North and South America (Smith et al., 2007; Glascock, 2011), Western Mediterranean (Francaviglia, 1988; Lugliè et al., 2014) inter alia. As a surface analysis, when used in non-destructive mode this method is sensitive to eventual surface irregularities and weathering, and to the geometry and size/thickness of the samples (see Davis et al., 2011), all of which can often be a limiting factor when analysing excavated artefacts (Shackley, 2011). Conducted on appropriate samples, it however offers a fast analysis (5 to 15 min per sample), with quite a low cost associated compared to other methods (e.g. LAICP-MS, PIXE). At the CRP2A, the ED-XRF analyses are conducted with a Seiko SEA 6000vx analyser equipped with a Rh source $(50 \mathrm{kV} / 1 \mathrm{~mA})$ and a SDD Vortex detector, and allowing an automated analysis (stage travel: $330(\mathrm{X}) \times 250(\mathrm{Y}) \times 150(\mathrm{Z}) \mathrm{mm})$. The $3 \times 3 \mathrm{~mm}$ beam collimator allows avoiding eventual heterogeneities in the material, while the sample chamber dimensions $(580(\mathrm{~W}) \times 450(\mathrm{D}) \times 150(\mathrm{H}) \mathrm{mm}$ ) permits the analysis of large samples. The ED-XRF easily distinguishes between the main obsidian sources of the Aegean (see e.g. Carter and Contreras, 2012) and the Western Mediterranean area. In Fig. 5 is presented a Principal Component Analysis (PCA) made on clr (centered log-ratio; see Aitchison, 1982) transformed data ( $\mathrm{MnO}, \mathrm{Fe}_{2} \mathrm{O}_{3}, \mathrm{Zn}, \mathrm{Ga}, \mathrm{Rb}, \mathrm{Sr}, \mathrm{Y}$, and $\mathrm{Zr}$ contents) from 24 geological samples from the Western Mediterranean (see Lugliè et al., 2014), displaying the potential of the ED-XRF for this area. When applied to the artefacts of the archaeological sites considered (Fig. 6; 703 samples analysed from Corsica, Sardinia, 


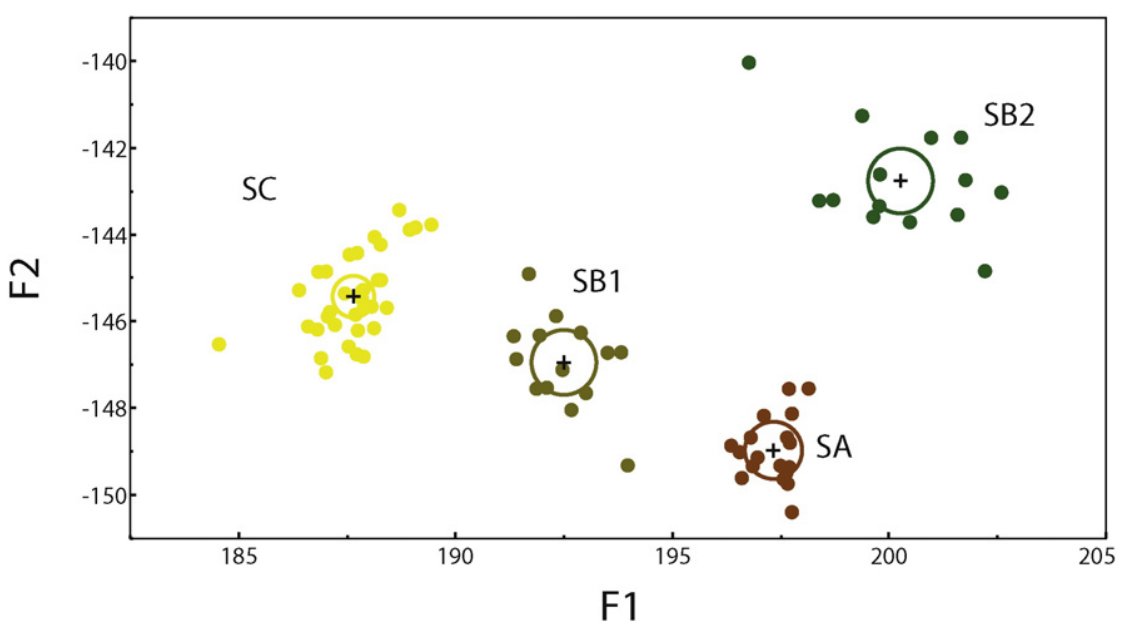

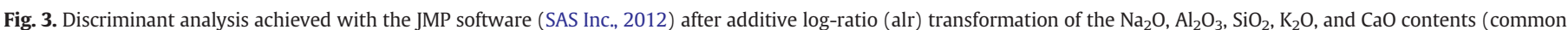

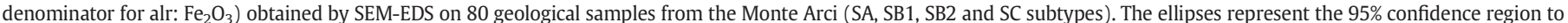

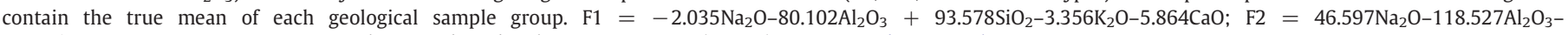
$3.385 \mathrm{SiO}_{2}+72.787 \mathrm{~K}_{2} \mathrm{O}+10.778 \mathrm{CaO}$. Analyses conducted at the IRAMAT-CRP2A (France); see Le Bourdonnec et al., 2010.

Southern France, and Northern Italy), the same PCA shows clear attributions to the different sources.

\subsection{Portable XRF}

Portable X-ray Fluorescence Spectroscopy [pXRF], is an ideal method for a non-destructive, fast and low-cost analysis of obsidian samples (Freund and Tykot, 2011; Le Bourdonnec et al., 2015c), offering the additional possibility to analyse samples directly on the site. Like ED-XRF, pXRF is sometimes considered as a 'surface' analysis, although the Xrays penetrate more in the sample than particles (electrons or protons), resulting in a probed volume of about a few $\mathrm{mm}^{3}$. Albeit sensitive to surface alterations (weathering), the limitations of the pXRF chiefly lies in the size and shape of the samples that can be analysed: the diameter of the beam ( $3 \mathrm{~mm}$ minimum for the instrument used here) restricts this method to samples with a flat surface, while their thickness should be of at least $3 \mathrm{~mm}$ in order to simplify the calculation of quantification by considering an 'infinite' target (although see Ferguson, 2012 for smaller dimension limits). Strictly non-destructive, its availability and rapidity makes it a method of choice for the analysis of large assemblages, whether it is located on the archaeological site itself, in a museum, or in the laboratory. The main elements necessary for the discrimination of the major obsidian sources in the Mediterranean (see e.g. Milić, 2014, Fig. 3 for the distinction between the Aegean sources) can be measured with pXRF, e.g. K, Ti, Mn, Fe, Zn, Rb, Sr, Zr, and Nb. A first series of analyses have been conducted by some members of our research group with a Niton XL3 Series analyser pXRF (RX tube: $50 \mathrm{kV}$; detector: Si-PIN) as part of a test program developed in collaboration with Philippe Dillmann from the LAPA laboratory (CEA/CNRS-IRAMAT UMR 5060 CNRS). A total of 41 geological samples from the Western Mediterranean have hence been geochemically characterised, as well as 343 artefacts from Corsica. Using the $(\mathrm{Rb} / \mathrm{Sr})$ and $(\mathrm{Zn} / \mathrm{Sr})$ log-ratios, the discrimination of the sources (Fig. 7) and the attribution of the archaeological samples (from Neolithic Corsica) is visibly made (Fig. 8).

\subsection{IBA-PIXE}

Among all the methods available within our research group, Particle Induced X-ray Emission spectroscopy [PIXE] is probably the less accessible and one of the most expensive. It indeed requires access to a particle accelerator, not uncommon but often quite inaccessible. Nevertheless, collaborations with the C2RMF (Centre de recherche

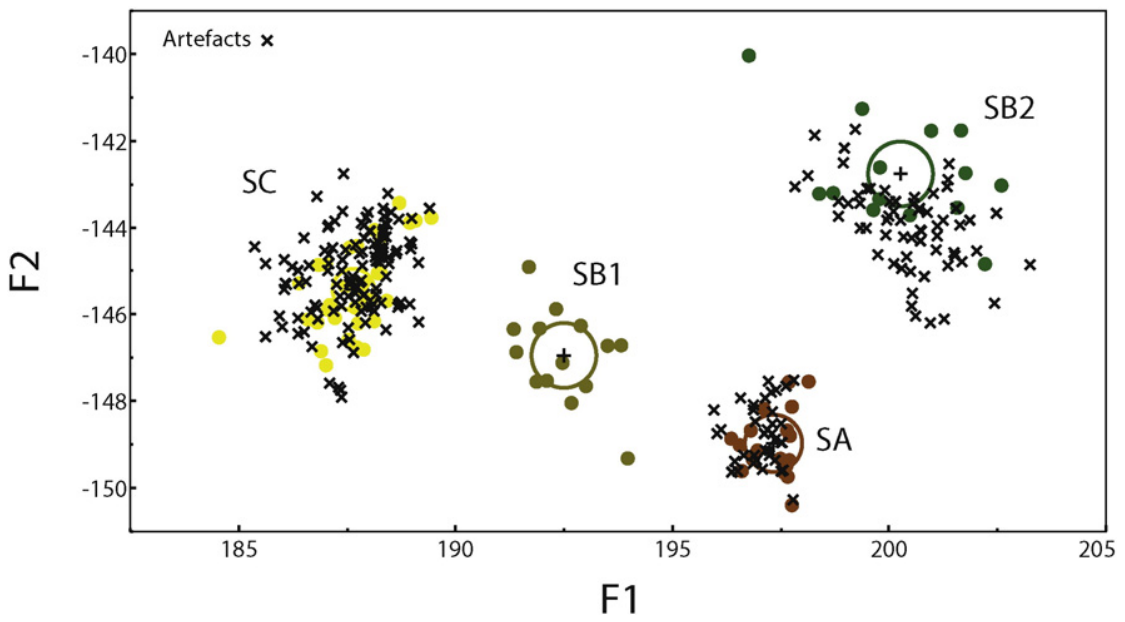

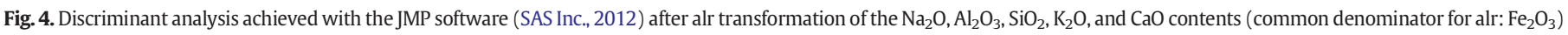

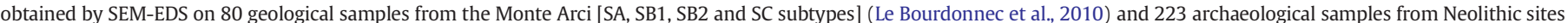

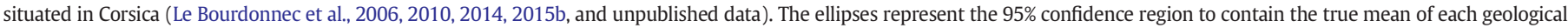

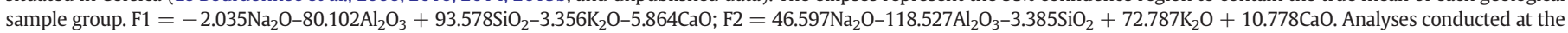
IRAMAT-CRP2A (France). 


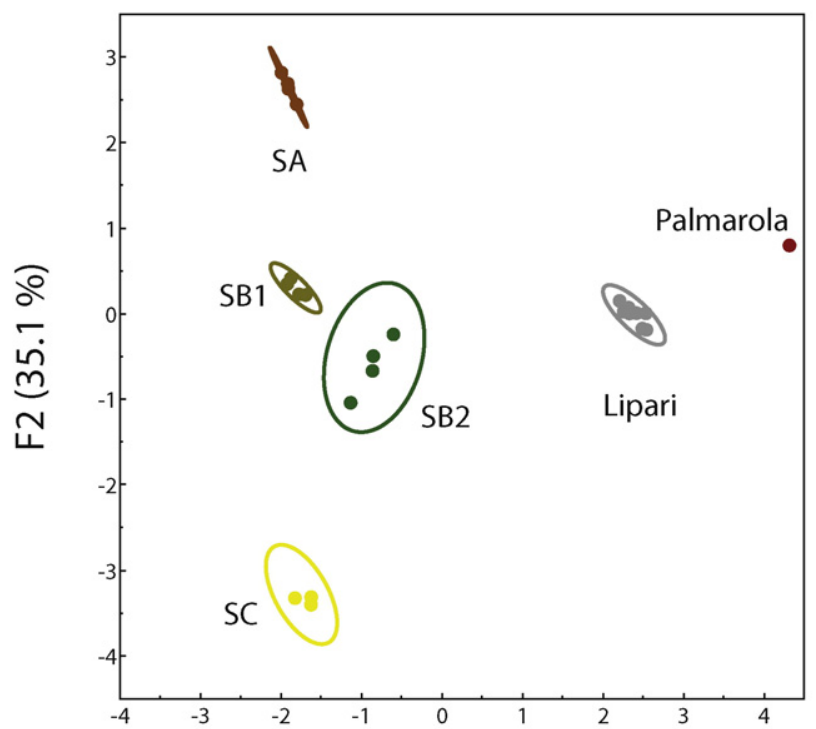

F1 (56.5\%)

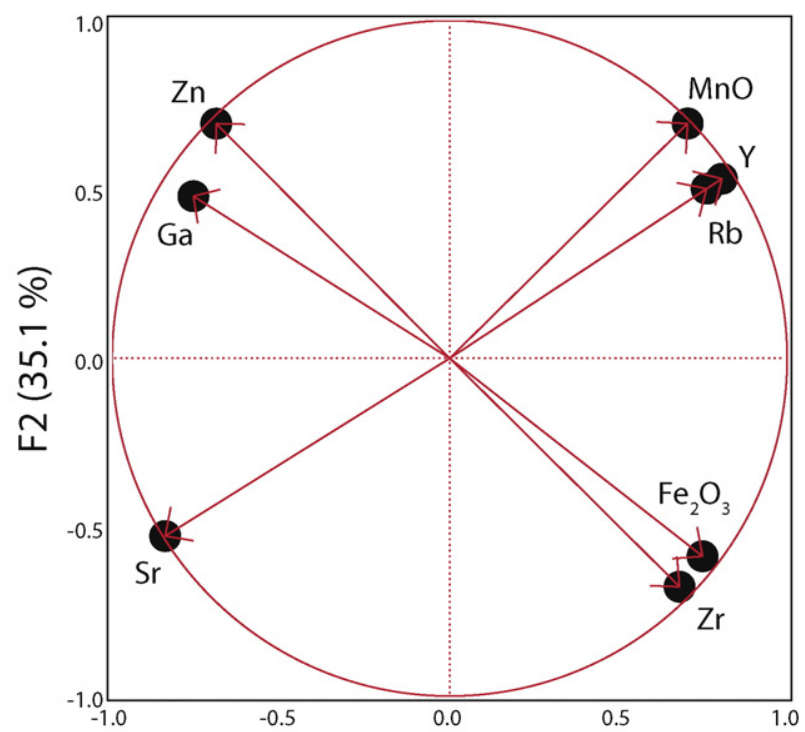

F1 (56.5\%)

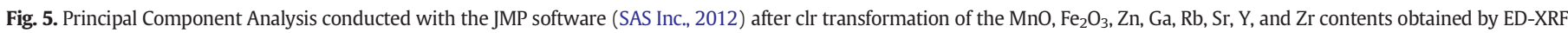
(IRAMAT-CRP2A) on 24 geological samples from the Western Mediterranean area. 99\% density ellipses. Data published in Lugliè et al., 2014, and unpublished data.

et de Restauration des Musées de France) in Paris and the CENBG (Centre Etudes Nucléaires de Bordeaux Gradignan) in Gradignan gave our research team the privilege of accessing this high-precision instrumentation. A total of 25 geological samples and 541 artefacts have been analysed thus far at the C2RMF in the AGLAE facility (Accélérateur Grand Louvre d'Analyses Elémentaires; Calligaro et al., 2002), which external micro-beam set-up allows for the analysis of larger samples (Le Bourdonnec et al., 2005, 2011). At the CENBG, the AIFIRA platform

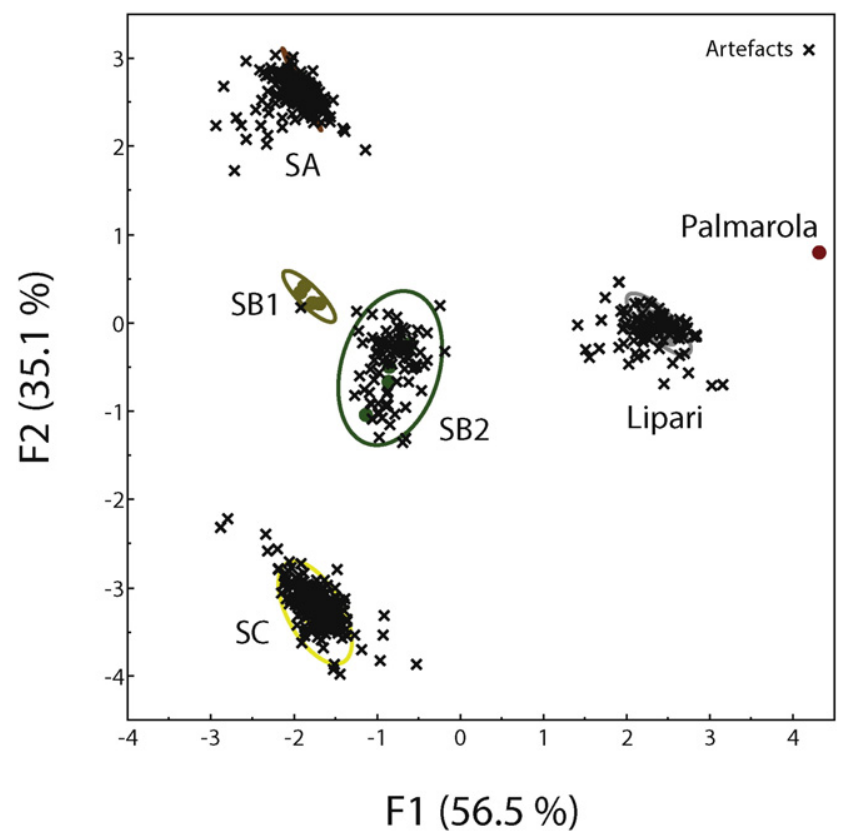

Fig. 6. Principal Component Analysis conducted with the JMP software (SAS Inc., 2012) after clr transformation of the $\mathrm{MnO}, \mathrm{Fe}_{2} \mathrm{O}_{3}, \mathrm{Zn}, \mathrm{Ga}, \mathrm{Rb}, \mathrm{Sr}, \mathrm{Y}$, and $\mathrm{Zr}$ contents obtained by ED-XRF (IRAMAT-CRP2A) on 24 geological samples (Western Mediterranean) and 703 archaeological samples (from Corsica, Sardinia, Southern France, and Northern Italy; Neolithic period). 99\% density ellipses. Data published in Lugliè et al., 2014, and unpublished data.
(Applications Interdisciplinaires de Faisceaux d'Ions en Région Aquitaine) presents a nuclear microprobe capable to analyse very small samples, due to its $5-\mu \mathrm{m}$ beam diameter (Llabador et al., 1990). A total of 30 obsidian geological samples and 134 artefacts were thus analysed at this facility. The PIXE has the capability to clearly distinguish the Aegean sources (see e.g. Bellot-Gurlet et al., 2008) as well as the Western Mediterranean sources by its ability to measure non-destructively major, minor and trace elements (here we measure $\mathrm{Na}_{2} \mathrm{O}, \mathrm{Al}_{2} \mathrm{O}_{3}, \mathrm{SiO}_{2}, \mathrm{~K}_{2} \mathrm{O}$,

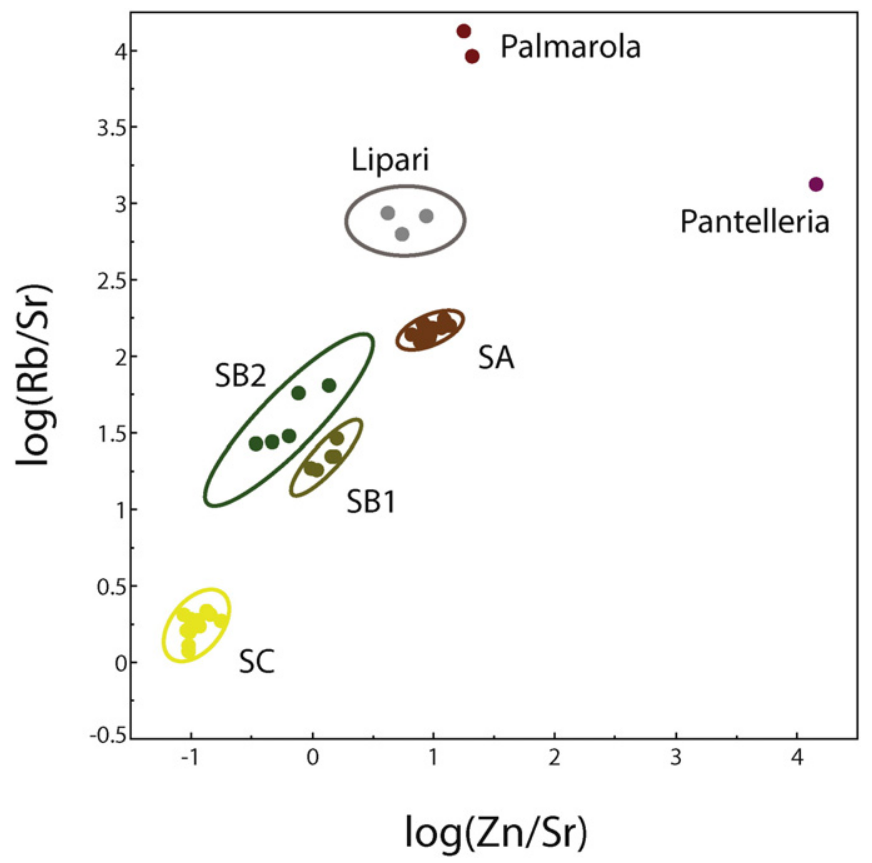

Fig. 7. Comparison of the $\log (\mathrm{Zn} / \mathrm{Sr})$ and $\log (\mathrm{Rb} / \mathrm{Sr})$ ratios obtained by pXRF for 41 geological samples from the Western Mediterranean area. 99\% density ellipses. Nondestructive analysis conducted with a NitonXL3 Series analyser pXRF (RX tube: $50 \mathrm{kV}$; detector: Si-PIN), as part of the program-test LAPA (CEA/CNRS-IRAMAT UMR5060 CNRS). Data published in Le Bourdonnec et al., 2015c. 


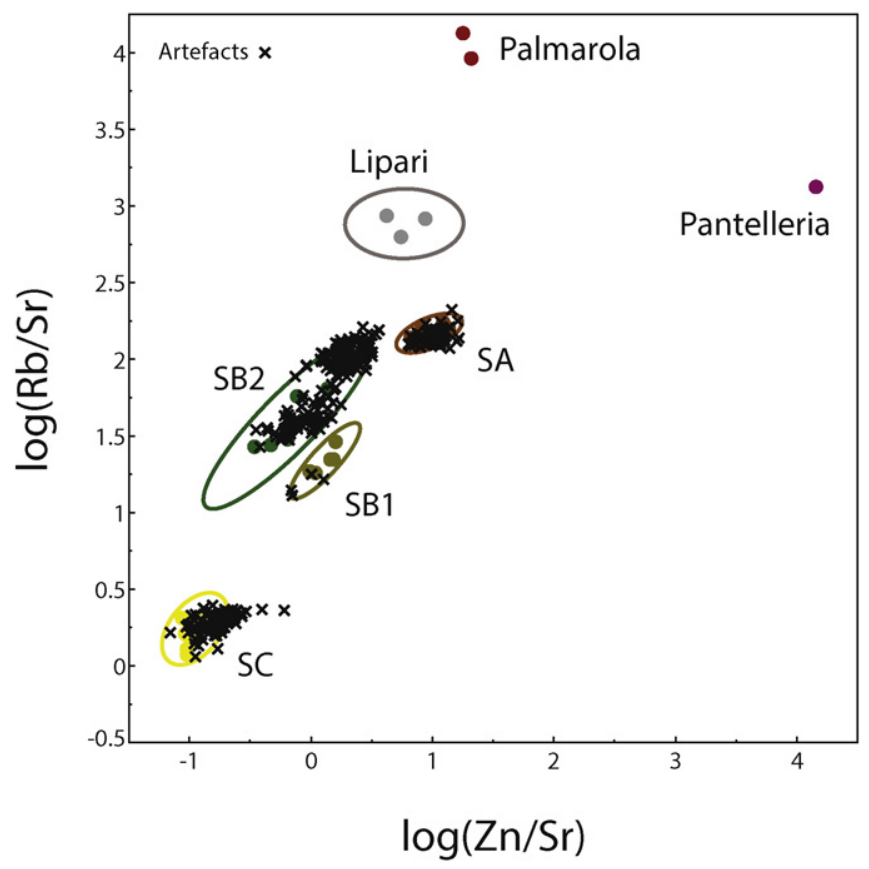

Fig. 8. Comparison of the $\log (\mathrm{Zn} / \mathrm{Sr})$ and $\log (\mathrm{Rb} / \mathrm{Sr})$ ratios obtained by pXRF for 41 geological samples from the Western Mediterranean area (Le Bourdonnec et al., 2015c) and 343 archaeological samples from Corsica (unpublished data). 99\% density ellipses. Non-destructive analysis conducted with a NitonXL3 Series analyser pXRF, as part of the program-test LAPA (CEA/CNRS-IRAMAT UMR5060 CNRS).

$\mathrm{CaO}, \mathrm{TiO}_{2}, \mathrm{MnO}, \mathrm{Fe}_{2} \mathrm{O}_{3}, \mathrm{Zn}, \mathrm{Ga}, \mathrm{Rb}, \mathrm{Sr}, \mathrm{Y}, \mathrm{Zr}$, and $\mathrm{Nb}$ ). For the latter, this can clearly be shown by a binary diagram involving the $(\mathrm{MnO} / \mathrm{Zr})$, ( $\mathrm{Rb} / \mathrm{Zn}),(\mathrm{Zn} / \mathrm{Zr})$, and ( $\mathrm{Rb} / \mathrm{Zr}) \log$ ratios (Figs. 9 and 10). Once applied to the artefacts (Sardinia, Southern France, Corsica, and Tunisia), the

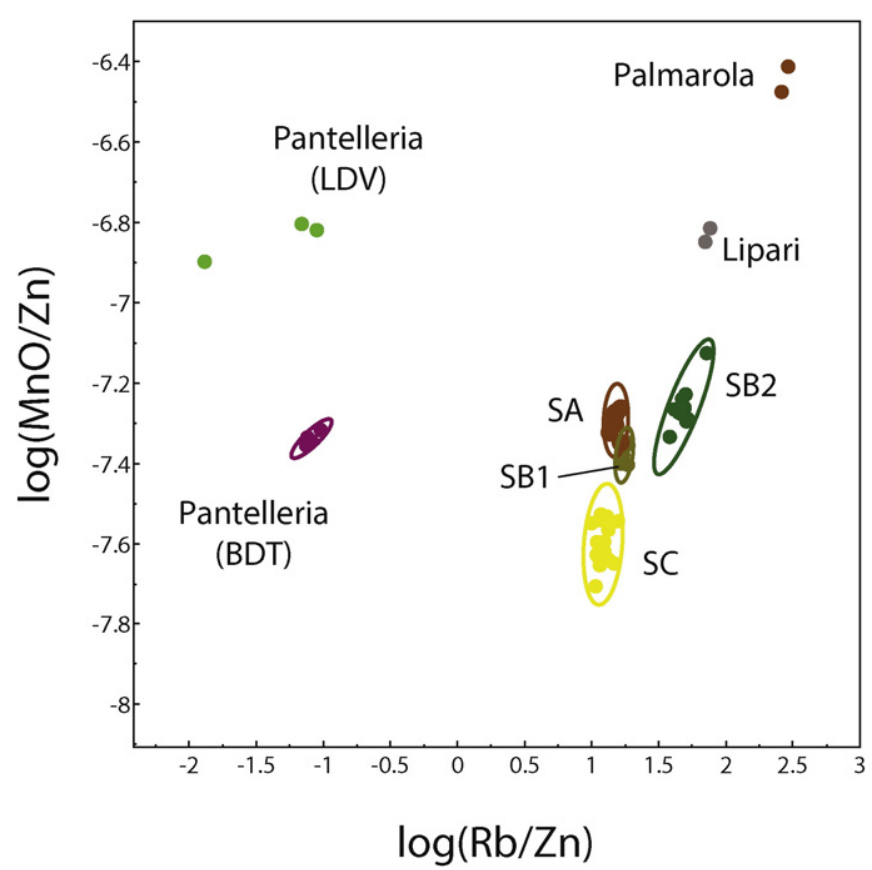

Fig. 9. Comparison of the $\log (\mathrm{Rb} / \mathrm{Zn})$ and $\log (\mathrm{MnO} / \mathrm{Zn})$ ratios obtained by PIXE (CENBG AIFIRA) for 55 geological samples from the Western Mediterranean area (see Lugliè et al., 2007, 2008a, 2009; Mulazzani et al., 2010; Poupeau et al., 2000). 99\% density ellipses. Data published in Lugliè et al., 2007, 2008a, 2009; Mulazzani et al., 2010; Poupeau et al., 2000.

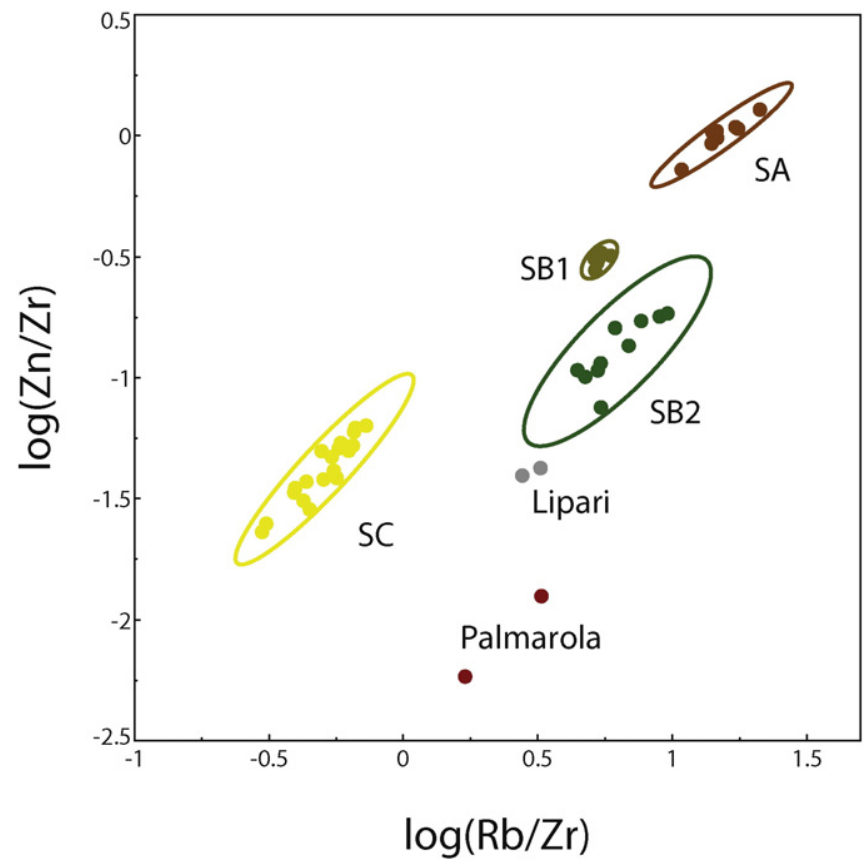

Fig. 10. Comparison of the $\log (\mathrm{Rb} / \mathrm{Zr})$ and $\log (\mathrm{Zn} / \mathrm{Zr})$ ratios obtained by PIXE (CENBG, AIFIRA) for 44 geological samples from the Western Mediterranean area; focus on the sources of Sardinia (Monte Arci: SA, SB1, SB2, SC), Lipari, and Palmarola. 99\% density ellipses. Data published in Lugliè et al., 2007, 2008a, 2009; Mulazzani et al., 2010; Poupeau et al., 2000.

same diagrams (Figs. 11 and 12) confirm its potential to attribute archaeological samples of unknown origin to one of those sources. Presenting no volumetric constraint, one should note that this method is however sensitive to surface alterations.

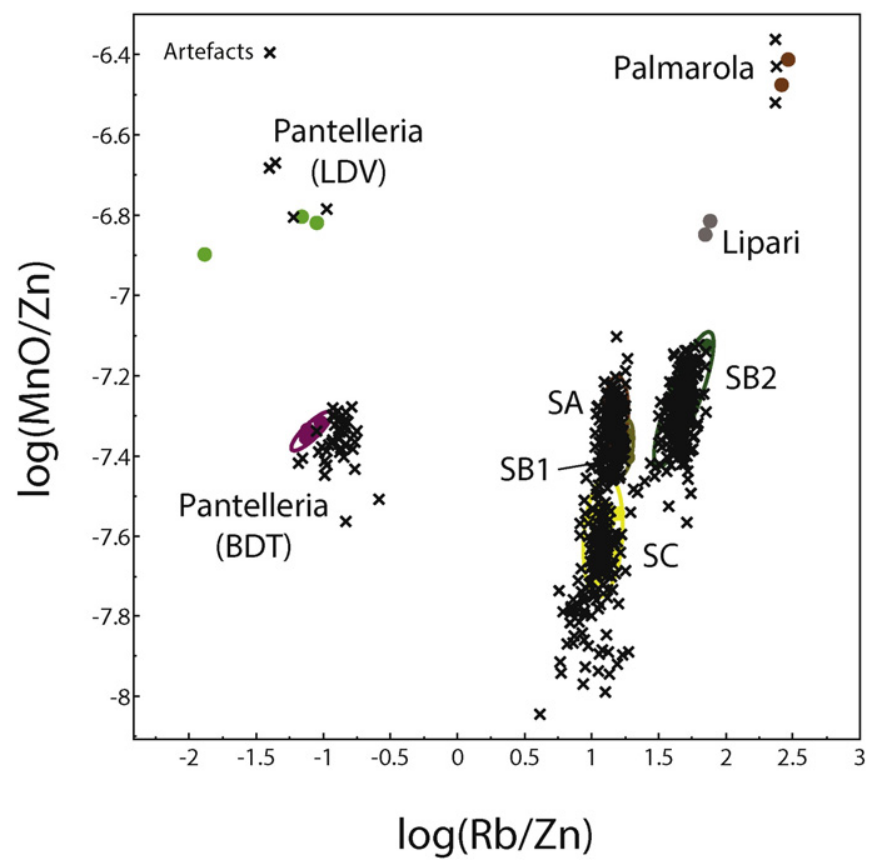

Fig. 11. Comparison of the $\log (\mathrm{Rb} / \mathrm{Zn})$ and $\log (\mathrm{MnO} / \mathrm{Zn})$ ratios obtained by PIXE (CENBG, AIFIRA) for 55 geological samples from the Western Mediterranean area (see Lugliè et al., 2007, 2008a, 2009; Mulazzani et al., 2010; Poupeau et al., 2000) and 675 archaeological samples from Sardinia, Southern France, Corsica, and Tunisia. 99\% density ellipses. Bressy et al., 2008; Le Bourdonnec, 2007; Le Bourdonnec et al., 2010, 2015a, 2015b; Lugliè et al., 2007, 2008a, 2008b, 2009; Poupeau et al., 2000; and unpublished data. 


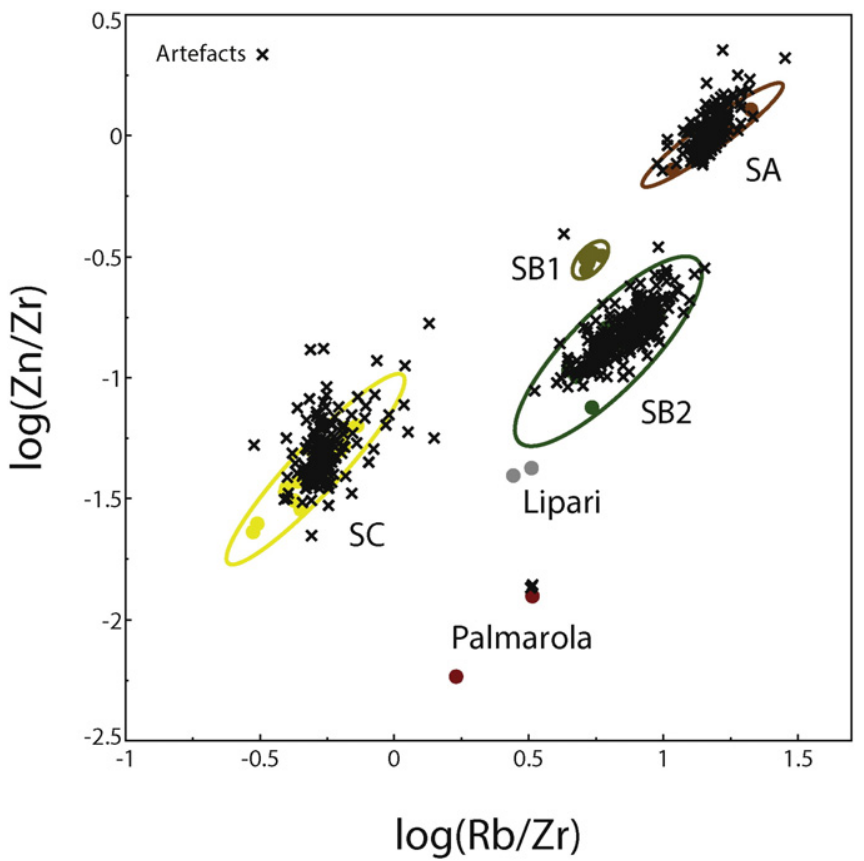

Fig. 12. Comparison of the $\log (\mathrm{Rb} / \mathrm{Zr})$ and $\log (\mathrm{Zn} / \mathrm{Zr})$ ratios obtained by PIXE (CENBG, AIFIRA) for 44 geological samples (99\% density ellipses) (Lugliè et al., 2007, 2008a, 2009 ; Poupeau et al., 2000) and 626 archaeological samples (Bressy et al., 2008; Le Bourdonnec, 2007; Le Bourdonnec et al., 2010, 2015b; Lugliè et al., 2007, 2008a, 2008b, 2009; Poupeau et al., 2000 and unpublished data).

\subsection{LA-ICP-MS}

Much like the PIXE, LA-ICP-MS is a less available, more expensive geochemical characterisation technique. However, it has several advantages that make it an ideal complement to other, more easily accessible methods. LA-ICP-MS is considered a 'virtually' nondestructive technique, i.e. the ablation performed is invisible to the naked eye (between 20 and $200 \mu \mathrm{m}$ width). This sampling procedure preserves the integrity of the sample, allowing for further characterisation analyses with other methods, but also use-wear and typotechnological studies, or even a potential exhibition in a museum. Albeit subject to controversy, the ablation process presents the advantage to overcome eventual surface alterations present on the sample. Furthermore, the area required is so small that it increases our chances to analyse samples with a relatively irregular surface; this is also greatly facilitated by the live image of the sample provided by the camera located in the ablation chamber, which allows choosing the most suitable - i.e. flat and unaltered - zone for the ablation. The LA-ICP-MS also delivers a fast analysis (only a few minutes per sample) with limited sample manipulations, since up to 100 samples can be placed at the same time in our chamber cell $(15 \times 15 \mathrm{~cm})$, depending on their size. It produces highly precise and accurate results (Gratuze et al., 2001) and offers the ability to measure up to 30 elements with very low detection limits (Russo et al., 2002). The protocol developed during the last two years by our research team at the SOLARIS laboratory at Southern Cross University, using an ESI (Electro Scientific Industries, Inc.) NW213 Laser Ablation System (solid state Nd-YAG deep UV [213 nm]) coupled to an Agilent $7700 \times$ ICP-MS, is tailored to the analysis of Western Mediterranean and Aegean obsidians (Orange et al., submitted for publication). Taking into account the major issues reported to occur with LA-ICPMS analysis such as elemental fractionation (see e.g. Jackson, 2001; Russo et al., 2002; Speakman and Neff, 2005), our protocol uses ablation lines and measures 14 isotopes $\left(^{28} \mathrm{Si},{ }^{45} \mathrm{Sc},{ }^{66} \mathrm{Zn},{ }^{85} \mathrm{Rb},{ }^{88} \mathrm{Sr},{ }^{89} \mathrm{Y},{ }^{90} \mathrm{Zr}\right.$, ${ }^{93} \mathrm{Nb},{ }^{133} \mathrm{Cs},{ }^{137} \mathrm{Ba},{ }^{146} \mathrm{Nd},{ }^{147} \mathrm{Sm},{ }^{208} \mathrm{~Pb},{ }^{232} \mathrm{Th}$, and ${ }^{238} \mathrm{U}$ ) to distinctly

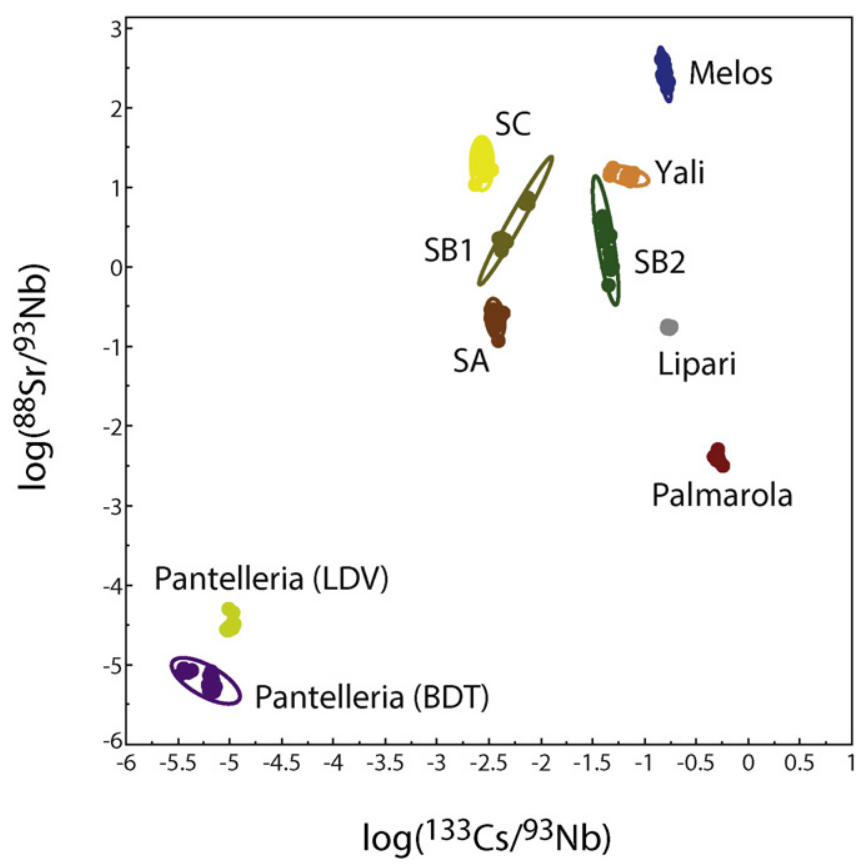

Fig. 13. Comparison of the $\log \left({ }^{133} \mathrm{Cs} /{ }^{93} \mathrm{Nb}\right)$ and $\log \left({ }^{88} \mathrm{Sr} /{ }^{93} \mathrm{Nb}\right)$ ratios obtained by LA-ICPMS (SOLARIS, SCU) for 175 geological samples from the Western Mediterranean and the Aegean area. 99\% density ellipses. Orange et al. submitted for publication.

discriminate between the sources, and to attribute artefacts to those sources. In less than 2 years, 175 geological samples from the Western Mediterranean and Aegean areas, as well as 538 artefacts from Corsican Neolithic sites were successfully characterised with this new optimized protocol, as shown here by a simple binary diagram opposing the logarithmic transformation of the $\left({ }^{88} \mathrm{Sr} /{ }^{93} \mathrm{Nb}\right)$ and $\left({ }^{133} \mathrm{Cs} /{ }^{93} \mathrm{Nb}\right)$ ratios (Figs. 13 and 14).

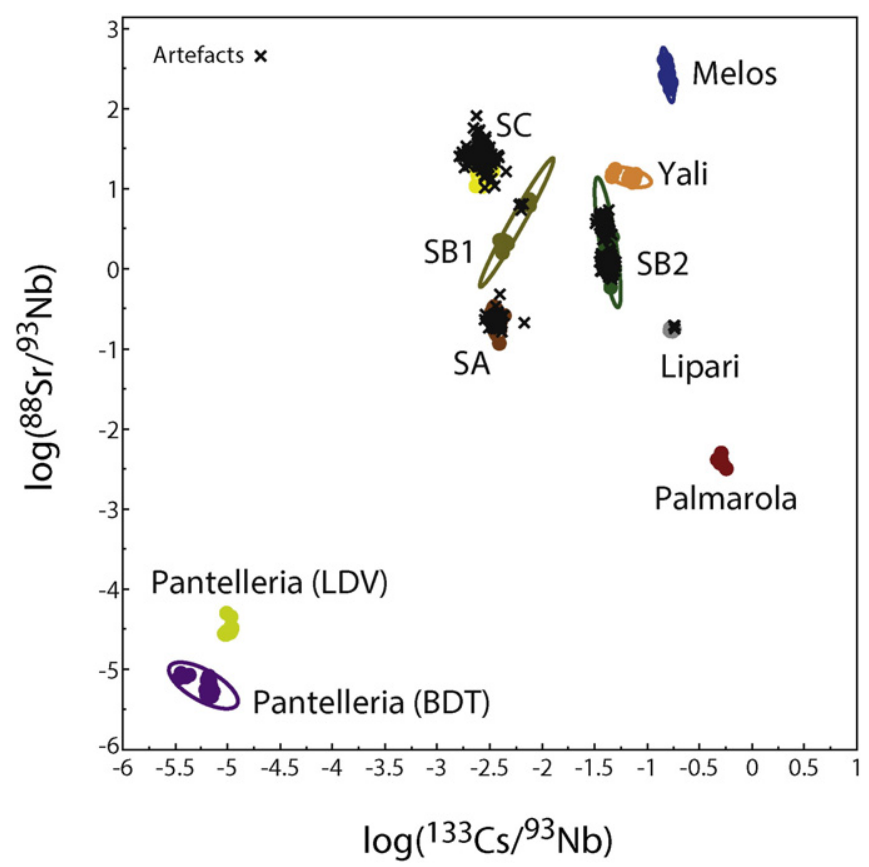

Fig. 14. Comparison of the $\log \left({ }^{133} \mathrm{Cs} /{ }^{93} \mathrm{Nb}\right)$ and $\log \left({ }^{88} \mathrm{Sr} /{ }^{93} \mathrm{Nb}\right)$ ratios obtained by LA-ICPMS (SOLARIS, SCU) for 175 geological samples from the Western Mediterranean and the Aegean area (Orange et al., submitted for publication) and 538 archaeological samples (Neolithic levels, Corsica). 99\% density ellipses. 


\section{Discussion}

When designing an obsidian sourcing study, several objectives have to be fulfilled:

- A diachronic and synchronic selection of well-documented assemblages

- An exhaustive characterisation of those assemblages

- A non-destructive or partially/virtually non-destructive analysis.

These objectives ensure that (a) the produced results are included in the general archaeological debate, (b) conclusions can be made on the overall obsidian economy of the site, and (c) the integrity of the archaeological samples is preserved and further analyses (use-wear, typotechnology, etc.) can still be performed on the artefacts when returned to the archaeologist.

To this end, a number of interdependent challenges and decisions that arise from either the assemblage's characteristics or the project's specifics, and constituting the limiting factors of the study, must be considered:

- Availability of the assemblage - determines if the samples can be analysed in the laboratory or if an in-situ analysis is required

- Budget and deadline

- Number of samples within the assemblage

- Samples' size, geometry, and surface state (possible alterations, weathering)

- Type of analysis requested by the Archaeologist/Heritage authorities destructive or non-destructive

- Geographical area - chosen method (or synergies between methods) will depend on the 'geochemical complexity' of the potential sources considered

- Availability of the instrument(s)

Some of those considerations will deeply influence the choice of the characterisation method, since each has its own limitations and advantages. Designing an analytical strategy implies to take into consideration each technique's capacities to achieve the characterisation of every artefact regardless of its size, shape or surface state. This is the concept summarised in Fig. 15.

The first step of our analytical strategy is to consider visual sourcing, easily available within our research group (CL). As described previously, this method can allow an initial screening and sorting of an assemblage, without any further instrumentation other than the naked eye of an experimented observer. The synergy with typo-technological studies is advantageous because the study of the assemblage will drive an eventual sampling, or reveal the refitting of some artefacts, thus reducing the required analyses. It also helps to obtain an idea on all the samples' size, shape and surface state for further analysis. Any sample that can be attributed to a potential source can then be set aside, while smallest samples or those presenting a high thickness and/or surface alterations preventing an easy visual characterisation can be redirected to analytical techniques. If the archaeologist allows a partially destructive analysis, the relatively flat samples exempt from major surface alterations and of sufficient dimensions can be analysed by SEM-EDS. If a non-destructive approach is recommended, ED-XRF or pXRF methods are primarily considered, due to their availability and relatively limited cost. Nevertheless, most assemblages also present small, thin, irregular and/ or altered artefacts that cannot be characterised by the aforementioned methods. For those, analyses by LA-ICP-MS or PIXE have to be conducted. Mainly, the PIXE presents the advantage of having no volumetric constraint, while the only real limitation with the LA-ICP-MS is the size of the chamber in the laser ablation system.

The flexibility acquired by this multi-method strategy gives researchers the possibility to privilege the most important practical 'parameter' in each study, be it the cost of the analyses (fixed by the budget) or the timeframe (when a deadline has to be met). More importantly, relying on a flexible analytical strategy allows for an exhaustive characterisation of the studied assemblages. In our case, it enabled the successful sourcing of close to 10,000 archaeological objects in the last decade (see Table 1). One can argue why exhaustiveness is important or not, but we firmly believe that each artefact has 'a story to tell'. Several studies indeed indicated that isolated obsidian artefacts could originate from a different source than the rest of the assemblage (Orange et al., 2013; Carter et al., 2013, inter alia). Once coupled with the typo-technological data, such epiphenomenon can provide substantial information on the population under study, in addition to what has been

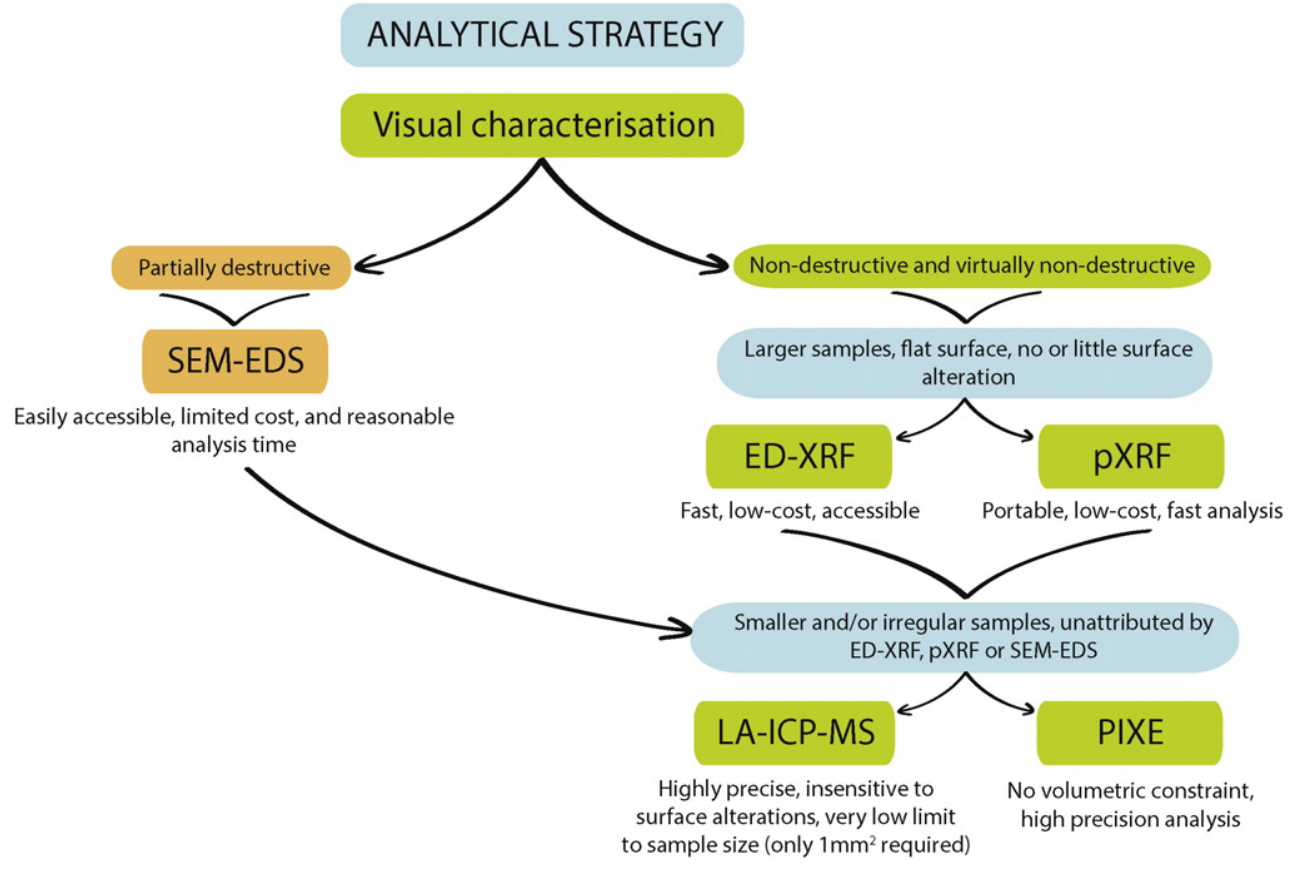

Fig. 15. Concept and unfolding of the analytical strategy for obsidian sourcing studies. 
Table 1

Number of obsidian archaeological samples sourced with each method employed by our research group (2000 - 2015).

\begin{tabular}{lc}
\hline Sourcing method & Number of artefacts analysed \\
\hline Visual characterisation & 7459 \\
SEM-EDS & 223 \\
ED-XRF & 703 \\
pXRF & 343 \\
PIXE & 675 \\
LA-ICP-MS & 538 \\
TOTAL & 9941 \\
\hline
\end{tabular}

learnt from more common consumption and procurement patterns, e.g. a connection with a different population or contemporary site.

The potential of analytical strategies also depends on (and calls for) collaborative projects. Each researcher within the research group might be part of a different university and/or a different department (Geology, Archaeology, Anthropology, GeoScience, Chemistry, etc.), thus giving access to various laboratories and instrumentations. Most importantly, such diversity in the researchers' specialties and affiliations allows for multidisciplinary projects, where complementary fields of expertise are brought together to answer a more general archaeological question. Much like the complementarity of the methods themselves, the complementarity of the different skills certainly make a substantial difference to the way we consider and 'make' research, allowing to take it a few steps further (see e.g. Binder et al., 2011). In all cases, sourcing results should not be used and interpreted by themselves: a thorough typological and technological study should always accompany those results (Poupeau et al., 2007; Le Bourdonnec, 2007).

Finally, the adoption of such analytical strategy naturally raises and forces the issue of inter-comparability of the results. A thorough control of the method's reliability (accuracy, precision, reproducibility; see Hughes, 1998; Frahm, 2012b) through the use of international standards and regular checks is indeed required if one wants to be able to compare the obtained compositions and provenance assignments (see Speakman and Shackley, 2013), but also if we want to provide results that can be fully used in future studies. Our methods' validity and reliability has been demonstrated numerous times in our work (Le Bourdonnec et al., 2010; Poupeau et al., 2010; Orange et al., submitted for publication, inter alia).

\section{Conclusions}

As early as 1984, Francaviglia drew attention to the fact that there is no ideal method that would solve every issue encountered in the field of obsidian sourcing. Again in Shackley, (1998), Shackley raised the case, admitting that "[...] the problem design and the level of precision needed to address that design will determine which instrument is the best for a given project." ( $\mathrm{p}$. 7). The concept of analytical strategy introduced by our research group is thus not new, but it remains to be systematically applied. Nonetheless, there is nowadays a general awareness that the archaeological question should be at the centre of our preoccupations. Contrary to what happened in the past, the pursuit for more efficient and more precise sourcing techniques (see e.g. Frahm and Feinberg, 2013; Kudriavtsev et al., 2015; Yi and Jwa, 2016), the reassessment of 'older' methods (Frahm, 2012a), or even the multiplication of pXRF applications across the world (Craig et al., 2007; Jia et al., 2010; Burley et al., 2011; Sheppard et al., 2011; Milić, 2014, Neri et al., 2015, i.a.) are not conducted self-sufficiently anymore, e.g. for the only purpose of method development. This is an essential turn in the history of our field, one which can only help increase our understanding of the techno-economic behaviour of past populations.

In conclusion, when focusing on an archaeological question the emphasis should be put on the design of a flexible analytical strategy customised for each specific and particular lithic assemblage. This type of approach has been adopted by our research group since 2003, and is reflected in the various studies published since (see e.g. Bressy et al., 2008; Carter et al., 2008; Lugliè et al., 2008a; Orange et al., 2013; Le Bourdonnec et al., 2014). As explained above, this facilitates the exhaustive characterisation of lithic assemblages, while optimizing both the time and cost of the analyses. It also allows for a cross-validation of the results when the same samples can be analysed by two or more methods, and most importantly initiate and maintain national and international collaborations between laboratories. Last but not least, we must insist again on the fact that the use of an analytical strategy is quite useless if not applied to well-documented assemblages, and fully integrated with typological and technological study of those assemblages (Poupeau et al., 2009; Le Bourdonnec, 2007), as it has already been the case in several studies (see e.g. Lugliè et al., 2007, 2009; Carter et al., 2006; Gibaja et al., 2013; Le Bourdonnec et al., 2014).

While the general picture of obsidian diffusion and consumption in the Western Mediterranean is slowly being reconstituted (see Lugliè, 2012), further studies are constantly required to refresh and supplement our view of this particular phenomenon. This paper has shown how the adoption of analytical strategies can undeniably help optimise obsidian sourcing studies conducted in this aim.

\section{Acknowledgements}

The authors would like to thank all participants to the projects mentioned in this paper. At the IRAMAT-CRP2A, this concerns in particular Yannick Lefrais for his management of the SEM-EDS, Brigitte Spiteri for the sample preparation, and Pierre Machut. At the IRAMAT-LMC, we wish to thank Philippe Dillmann for his contribution to pXRF experiments. The authors are also grateful to present and former members of the CENBG for their precious help during the PIXE analyses: Philippe Alfaurt, Matthieu Compin, Laurent Daudin, Philippe Moretto, Laurent Serani, and Stéphanie Sorieul. At Arcane (Gradignan, France), the authors thank Hervé Guegan, Quy Le Minh, and Benoît Ridard. Finally, the authors wish to express their gratitude to Thomas Calligaro, JeanClaude Dran, Thiéry Guillou, Quentin Lemasson, Brice Moignard, Claire Pacheco, Laurent Pichon, and Joseph Salomon† from the C2RMF.

Marie Orange's Ph.D. is funded by a Postgraduate scholarship from Southern Cross University and by part of an Australian Research Council discovery grant [DP140100919]. This project has been financially supported by the Conseil Régional d'Aquitaine, the ANR (French National Research Agency; no. ANR-10-LABX-52), and the Université Bordeaux Montaigne PSE (Politique Scientifique d'Établissement). Part of the PIXE measures at AGLAE were funded by the Eu-Artech (ref. 06-05) and Charisma (ref 10-21) European programs.

\section{References}

Acquafredda, P., Lorenzoni, S., Zanettin, E., 1996. Discrimination of Melos, Lipari, Palmarola obsidian using SEM-EDS. In: Demirci, S., Özer, A.M., Summers, G.D. (Eds.), Proceedings of the 29th International Symposium on Archaeometry. Tübitak, Ankara, pp. 87-97.

Acquafredda, P., Andriani, T., Lorenzoni, S., Zanettin, E., 1999. Chemical characterization of obsidians from different Mediterranean sources by non-destructive SEM-EDS analytical method. J. Archaeol. Sci. 26, 315-325.

Aitchison, J., 1982. The statistical analysis of compositional data. J. R. Stat. Soc. Ser. B Methodol. 139-177.

Bellot-Gurlet, L., Pelon, O., Séfériadès, M.L., 2008. Détermination de provenance d'une sélection d'obsidiennes du palais minoen de Malia (Crète). C.R. Palevol 7, 419-427.

Binder, D., Gratuze, B., Mouralis, D., Balkan-Atlı, N., 2011. New investigations of the Göllüdağ obsidian lava flows system: a multi-disciplinary approach. J. Archaeol. Sci. 38, 3174-3184.

Bressy, C.S., D'Anna, A., Poupeau, G., Le Bourdonnec, F.-X., Bellot-Gurlet, L., Leandri, F., Tramoni, P., Demouche, F., 2008. Chert and obsidian procurement of three Corsican sites during the 6th and 5th millenniums BC. C.R. Palevol 7, 237-248.

Burley, D.V., Sheppard, P.J., Simonin, M., 2011. Tongan and Samoan volcanic glass: pXRF analysis and implications for constructs of ancestral Polynesian society. J. Archaeol Sci. 38, 2625-2632.

Calligaro, T., Dran, J.-C., Moignard, B., Pichon, L., Salomon, J., Walter, P., 2002. Ion beam analysis with external beams: recent set-up improvements. Nucl. Inst. Methods Phys. Res. B 188, 135-140.

Cann, J.R., Renfrew, C., 1964. The characterization of obsidian and its application to the Mediterranean Region. Proc. Prehist. Soc 30, 111-133. 
Carter, T., 2014. The contribution of obsidian characterization studies to early prehistoric archaeology. In: Yamada, M., Ono, A. (Eds.), Lithic Raw Material Exploitation and Circulation in Prehistory: A Comparative Perspective in Diverse Palaeoenvironments, ERAUL 138, pp. 23-33 (Liège, Belgique).

Carter, T., Shackley, M.S., 2007. Sourcing obsidian from Neolithic CatalHoyuk (Turkey) using energy dispersive X-ray fluorescence. Archaeometry 49, 437-454.

Carter, T., Contreras, D.A., 2012. The character and use of the Soros Hill Obsidian source, Antiparos (Greece). C.R. Palevol 11, 595-602.

Carter, T., Poupeau, G., Bressy, C., Pearce, N.J.G., 2006. A new programme of obsidian characterization at Çatalhöyük, Turkey. J. Archaeol. Sci. 33, 893-909.

Carter, T., Dubernet, S., King, R., Le Bourdonnec, F.X., Milić, M., Poupeau, G., Shackley, M.S. 2008. Eastern Anatolian obsidians at Catalhoyuk, and the reconfiguration of regional interaction in the Early Ceramic Neolithic. Antiquity 82, 900-909.

Carter, T., Grant, S., Kartal, M., Coşkun, A., Özkaya, V., 2013. Networks and Neolithisation: sourcing obsidian from Körtik Tepe (SE Anatolia). J. Archaeol. Sci. 40, 556-569.

Clark, J.-E., 1981. Multi-faceted approach to the study of Mesoamerican obsidian trade: an example from early Chiapas. Paper Presented at the 46th Annual Meeting of the Society for American Archaeology in San Diego, California.

Craig, N., Speakman, R.J., Popelka-Filcoff, R.S., Glascock, M.D., Robertson, J.D., Shackley, M.S., Aldenderfer, M.S., 2007. Comparison of XRF and PXRF for analysis of archaeological obsidian from southern Peru. J. Archaeol. Sci. 34, 2012-2024.

Davis, M.K., 1994. Bremsstrahlung ratio technique applied to the non-destructive energydispersive X-ray fluorescence analysis of obsidian. Int. Assoc. Obsidian Stud. Bull. 11, 9-10.

Davis, M.K., Jackson, T., Shackley, M.S., Teague, T., Hampel, J., 2011. Factors affecting the energy-dispersive X-ray fluorescence (EDXRF) analysis of archaeological obsidian. In: Shackley, M.S. (Ed.), X-Ray Fluorescence Spectrometry (XRF) in Geoarchaeology. Springer, New York, pp. 45-63.

De Francesco, A.M., Crisci, G.M., Bocci, M., 2008. Non-destructive analytic method using $\mathrm{XRF}$ for determination of provenance of archaeological obsidians from the Mediterranean area: a comparison with traditional XRF methods. Archaeometry 50, 337-350.

De Francesco, A., Bocci, M., Crisci, G.M., 2011. Non-destructive applications of wavelength XRF in obsidian studies. In: Shackley, M.S. (Ed.), X-Ray Fluorescence Spectrometry (XRF) in Geoarchaeology. Springer, New York, pp. 81-107.

Elam, J.M., 1993. Post-Formative Obsidian Exchange in Oaxaca, Mexico (PhD Dissertation) University of Missouri, Columbia.

Ferguson, J.R., 2012. X-Ray fluorescence of obsidian: approaches to calibration and the analysis of small samples. In: Shugar, A.N., Mass, J.L. (Eds.), Handheld XRF for Art and Archaeology. Leuven University Press, Leuven, pp. 401-422.

Forster, N., Grave, P., 2012. Non-destructive PXRF analysis of museum-curated obsidian from the Near East. J. Archaeol. Sci. 39, 728-736.

Frahm, E., 2012a. Non-destructive sourcing of bronze age near eastern obsidian artefacts: redeveloping and reassessing electron microprobe analysis for obsidian sourcing. Archaeometry 54, 623-642.

Frahm, E., 2012b. Evaluation of archaeological sourcing techniques: reconsidering and re deriving hughes' four-fold assessment scheme. Geoarchaeology 27, 166-174.

Frahm, E., Feinberg, J.M., 2013. From flow to quarry: magnetic properties of obsidian and changing the scale of archaeological sourcing. J. Archaeol. Sci. 40, 3706-3721.

Frahm, E., Doonan, R., Kilikoglou, V., 2014. Handheld portable X-ray fluorescence of aegean obsidians. Archaeometry 56 (2), 228-260.

Francaviglia, V., 1984. Characterization of Mediterranean obsidian sources by classical petrochemical methods. Preistoria Alpina 20, 311-332.

Francaviglia, V., 1988. Ancient obsidian sources on Pantelleria (Italy). J. Archaeol. Sci. 15, 109-122.

Freund, K.P., 2013. An assessment of the current applications and future directions of obsidian sourcing studies in archaeological research. Archaeometry 55, 779-793.

Freund, K.P., Tykot, R.H., 2011. Lithic technology and obsidian exchange networks in bronze age Nuragic Sardinia (Italy). Archaeol. Anthropol. Sci. 3, 151-164.

Gibaja, J.F., Lea, V., Lugliè, C., Bosch, J., Gassin, B., Terradas-Batlle, X., 2013. Between sardinia and catalonia: contacts and relationships during the Neolithic. Proceedings of the International Congress "Gorosti U5b3" (Cagliari-Alghero, June 12-16, 2012). Le Monnier Università, Mondadori Education S.p.A., Milano, pp. 214-233.

Glascock, M.D., 2011. Comparison and contrast between XRF and NAA: used for characterization of obsidian sources in central Mexico. In: Shackley, M.S. (Ed.), X-Ray Fluorescence Spectrometry (XRF) in Geoarchaeology. Springer, New York, pp. 161-192.

Glascock, M.D., Braswell, G.E., Cobean, R.H., 1998. A systematic approach to obsidian source characterization. In: Shackley, M.S. (Ed.), Archaeological Obsidian Studies, Method and TheoryAdvances in Archaeological and Museum Science 3. Plenum Press, New York and London, pp. 15-65.

Gonnermann, H.M., Manga, M., 2005. Flow banding in obsidian: a record of evolving textural heterogeneity during magma deformation. Earth Planet. Sci. Lett. 236, 135-147.

Gratuze, B., Barrandon, J.N., Al Isa, K., Cauvin, C., 1993. Non-destructive analysis of obsidian artefacts using nuclear techniques: investigations of provenance of near Eastern Artefacts. Archaeometry 35 (1), 11-21.

Gratuze, B., Blet-Lemarquand, M., Barrandon, J.N., 2001. Mass spectrometry with laser sampling: a new tool to characterize archaeological materials. J. Radioanal. Nucl. Chem. 247, 645-656.

Hall, M., Kimura, H., 2002. Quantitative EDXRF Studies of obsidian sources in Northern Hokkaido. J. Archaeol. Sci. 29, 259-266.

Hughes, R.E., 1998. On reliability, validity, and scale in obsidian sourcing research. In Ramenofsky, A.F., Steffen, A. (Eds.), Unit Issues in Archaeology: Measuring Time, Space, and Material. University of Utah Press, Salt Lake City, pp. 103-114.

Ikeya, N., 2014. Identification of archaeological obsidian sources in Kanto and Chubu Regions (Central Japan) by energy dispersive X-ray fluorescence analysis. In: Ono, A., Glascock, M.D., Kuzmin, Y.V., Suda, Y. (Eds.), Methodological Issues for
Characterisation and Provenance Studies of Obsidian in Northeast Asia, BAR International Series 2620. Archaeopress, Oxford, England, pp. 111-124.

Jackson, S., 2001. The application of Nd:YAG lasers in LA-ICP-MS. In: Sylvester, P. (Ed.), Laser-Ablation-ICPMS in the Earth sciences: principles and applications. Mineralogical Association of Canada, St Johns, Newfoundland, pp. 29-46.

Jia, P.W., Doelman, T., Chen, C., Zhao, H., Lin, S., Torrence, R., Glascock, M.D., 2010. Moving sources: a preliminary study of volcanic glass artifact distributions in northeast China using PXRF. J. Archaeol. Sci. 37, 1670-1677.

JMP®, 2012. Version 10.0.2. SAS Institute Inc., Cary, NC.

Kudriavtsev, Y., Gallardo, S., Avendaño, M., Ramírez, G., Asomoza, R., Manzanilla, L., Beramendi, L., 2015. Chemical analysis of obsidian by a SIMS/EDX combined system. Nucl. Instrum. Methods Phys. Res., Sect. B 343, 153-157.

Le Bourdonnec, F.X., 2007. Aspects archéométriques de la circulation de l'obsidienne Préhistorique. Développements analytiques et applications en Corse, Sardaigne et Éthiopie. Université Michel de Montaigne Bordeaux 3, France (Ph.D. Dissertation).

Le Bourdonnec, F.X., Delerue, S., Dubernet, S., Moretto, P., Calligaro, T., Dran, J.C., Poupeau, G., 2005. PIXE characterization of Western Mediterranean and Anatolian obsidians and Neolithic provenance studies. Nucl. Instrum. Methods Phys. Res., Sect. B 240, 595-599.

Le Bourdonnec, F.-X., Poupeau, G., Lugliè, C., 2006. SEM-EDS analysis of western Mediterranean obsidians: a new tool for Neolithic provenance studies. Compt. Rendus Geosci. 338, 1150-1157.

Le Bourdonnec, F.-X., Bontempi, J.-M., Marini, N., Mazet, S., Neuville, P.F., Poupeau, G., Sicurani, J., 2010. SEM-EDS characterization of western Mediterranean obsidians and the Neolithic site of A Fuata (Corsica). J. Archaeol. Sci. 37, 92-106.

Le Bourdonnec, F.-X., Poupeau, G., Lugliè, C., D'Anna, A., Bellot-Gurlet, L., Bressy-Leandri, C.S., Pasquet, A., Tramoni, P., 2011. New data and provenance of obsidian blocks from Middle Neolithic contexts on Corsica (western Mediterranean). C.R. Palevol 10, 259-269.

Le Bourdonnec, F.-X., Poupeau, G., Lorenzi, F., Machut, P., Sicurani, J., 2014. Typologie et provenance de l'obsidienne du site néolithique d'A Guaita (NW Cap Corse, Corse, France). C.R. Palevol 13, 317-331.

Le Bourdonnec, F.-X., Poupeau, G., Boussofara, R., Dubernet, S., Moretto, P., Compin, M., Mulazzani, S., 2015a. Obsidians from the Kerkennah Islands (eastern Tunisia) and the PIXE elemental compositions of the Mediterranean peralkaline obsidians. Nucl. Inst. Methods Phys. Res. B 358, 271-275.

Le Bourdonnec, F.-X., D'Anna, A., Poupeau, G., Lugliè, C., Bellot-Gurlet, L., Tramoni, P., Marchesi, H., 2015b. Obsidians artefacts from Renaghju (Corsica Island) and the Early Neolithic circulation of obsidian in the Western Mediterranean. Archaeol. Anthropol. Sci. 7, 441-462.

Le Bourdonnec, F.-X., Bellot-Gurlet, L., Lugliè, C., Bressy-Leandri, C., 2015c. Archéométrie de l'obsidienne: déchiffrer la circulation d'une matière première. Nouv. Archeol. $138,23-27$.

Llabador, Y., Bertault, D., Gouillaud, J.C., Moretto, P., 1990. Advantages of high-speed scanning for microprobe analysis of biological samples. Nucl. Instrum. Methods Phys. Res., Sect. B 49, 435-440.

Lugliè, C., 2012. From the perspective of the source. Neolithic production and exchange of Monte Arci Obsidians (Central-Western Sardinia). Rubricatum: revista del Museu de Gavà, pp. 173-180.

Lugliè, C., Le Bourdonnec, F.-X, Poupeau, G., Atzeni, E., Dubernet, S., Moretto, P., Serani, L 2007. Early Neolithic obsidians in Sardinia (Western Mediterranean): the Su Carroppu case. J. Archaeol. Sci. 34, 428-439.

Lugliè, C., Le Bourdonnec, F.-X., Poupeau, G., Congia, C., Moretto, P., Calligaro, T., Sanna, I., Dubernet, S., 2008a. Obsidians in the Rio Saboccu (Sardinia, Italy) campsite: Provenance, reduction and relations with the wider Early Neolithic Tyrrhenian area. C.R. Palevol 7, 249-258.

Lugliè, C., Le Bourdonnec, F.X., Poupeau, G., Sanna, I., 2008b. Monte Arci obsidians Provenance in the Direct Procurement Zone: the case-study of Sa Punta-Marceddì (Central-Western Sardinia). In: Gueli, A. (Ed.), Scienza e Beni Culturali, Atti del V Congresso Nazionale di Archeometria (Siracusa, 26-29 Febbraio 2008), Morrone Editore, Siracusa, pp. 581-590.

Lugliè, C., Congia, C., Le Bourdonnec, F.X., Poupeau, G., Dubernet, S., Calligaro, T., Sanna, I., 2009. Obsidian economy in the Rio Saboccu open-air early neolithic site (Sardinia, Italy). Proceedings of the $\mathrm{XV}^{\text {th }}$ Congress of the International Union for Prehistoric and Protohistoric Sciences, Lisbon, September 4-9 2006. Archaeopress, Oxford, pp. 203-215.

Lugliè, C., Le Bourdonnec, F.X., Poupeau, G., 2011. Neolithic obsidian economy around the Monte Arci Source (Sardinia, Italy): the importance of integrated provenance/technology analyses. In: Turbanti-Memmi, I. (Ed.), Proceedings of the 37th International Symposium on Archaeometry, 12th - 16th May 2008, Siena, Italy. Springer, Verlag, Berlin, Heidelberg, pp. 255-260.

Lugliè, C., Le Bourdonnec, F.X., Poupeau, G., 2014. Caratterizzazione elementare e provenienza delle ossidiane mediante analisi non distruttiva PIXE e EDXRF. In: Venturino Gambari, M. (Ed.), La memoria del passato. Castello di Annone tra archeologia e storia. LineLab edizioni, Alessandria, pp. 333-336.

Milić, M., 2014. PXRF characterisation of obsidian from central Anatolia, the Aegean and central Europe. J. Archaeol. Sci. 41, 285-296.

Milić, M., Brown, K., Carter, T. 2013. The Chipped stone. Appendix 21.1. A visual characterization of the Çatalhöyük obsidian. In: Hodder, I. (Ed.), Substantive Technologies at Çatalhöyük: Reports from the 2000-08 Seasons, Çatalhöyük Research Project Series Volume 9, BIAA Monograph 48, Monumenta Archaeologica 31. British Institute at Ankara, London; Cotsen Institute of Archaeology Press, Los Angeles, pp. 1-7 (on CD).

Mulazzani, S., Le Bourdonnec, F.-X., Belhouchet, L., Poupeau, G., Zoughlami, J., Dubernet, S., Tufano, E., Lefrais, Y., Khedhaier, R., 2010. Obsidian from the Epipalaeolithic and Neolithic eastern Maghreb. A view from the Hergla context (Tunisia). J. Archaeol. Sci. 37, 2529-2537. 
Nadooshan, F.K., Abedi, A., Glascock, M.D., Eskandari, N., Khazaee, M., 2013. Provenance of prehistoric obsidian artefacts from Kul Tepe, northwestern Iran using X-ray fluorescence (XRF) analysis. J. Archaeol. Sci. 40, 1956-1965.

Neri, L.A.M., Pawlik, A.F., Reepmeyer, C., Mijares, A.S.B., Paz, V.J., 2015. Mobility of early islanders in the Philippines during the Terminal Pleistocene/Early Holocene boundary: pXRF-analysis of obsidian artefacts. J. Archaeol. Sci. 61, 149-157.

Orange, M., Carter, T., Le Bourdonnec, F.-X., 2013. Sourcing obsidian from Tell Aswad and Qdeir 1 (Syria) by SEM-EDS and EDXRF: Methodological implications. C.R. Palevol 12, 173-180.

Orange, M., Le Bourdonnec, F.-X., Scheffers, A., Joannes-Boyau, R. Sourcing obsidian in Archaeology: a new optimized LA-ICP-MS protocol. Science and Technology of Archaeological Research (submitted for publication).

Orange, M., Le Bourdonnec, F.-X., Bellot-Gurlet, L. Obsidian provenance analysis in Archaeology: 50 years of methodological developments. In: Chapoulie, R., Sepulveda, M., Wright, V. (Eds.), Manual de Arqueometria. IFEA editions, Lima, Peru (in press).

Pierce, D.E., 2015. Visual and geochemical analyses of obsidian source use at San Felipe Aztatán, Mexico. J. Anthropol. Archaeol. 40, 266-279.

Poupeau, G., Bellot-Gurlet, L., Brisotto, V., Dorighel, O., 2000. Nouvelles données sur la provenance de l'obsidienne des sites néolithiques du Sud-Est de la France. C.R. Acad. Sci., Ser. IIa: Sci. Earth Planet. Sci. 330, 297-303.

Poupeau, G., Le Bourdonnec, F.-X., Dubernet, S., Scorzelli, R.B., Duttine, M., Carter, T., 2007. Tendances actuelles dans la caractérisation des obsidiennes pour les études de provenance, ArchéoSciences. Rev. Archeomet. 31, 79-86.

Poupeau, G., Piboule, M., Le Bourdonnec, F.X., Dorighel, O., 2009. L'obsidienne, or noir de la Préhistoire. In: Moncel, M.H., Fröhlich, F. (Eds.), L'Homme et le précieuxMatières minérales précieuses. BAR International series 1934, Oxford, pp. 193-198.

Poupeau, G., Le Bourdonnec, F.-X., Carter, T., Delerue, S., Steven Shackley, M., Barrat, J.-A., Dubernet, S., Moretto, P., Calligaro, T., Milić, M., Kobayashi, K., 2010. The use of SEMEDS, PIXE and EDXRF for obsidian provenance studies in the Near East: a case study from Neolithic Çatalhöyük (central Anatolia). J. Archaeol. Sci. 37, 2705-2720.

Poupeau, G., Le Bourdonnec, F.X., Bellot-Gurlet, L., 2014. Caractérisation et circulation de l'obsidienne. In: Dillmann, P., Bellot-Gurlet, L. (Eds.), Circulation et provenance des matériaux dans les sociétés anciennes. Collection "Sciences Archéologiques", Éditions des Archives Contemporaines, Paris, pp. 9-33.

Renfrew, C., 1969. Trade and culture process in European prehistory. Curr. Anthropol. 10 (2/3), 151-169.

Renfrew, C., Dixon, J.E., Cann, J.R., 1966. Obsidian and early cultural contact in the Near East. Proc. Prehist. Soc 32, 30-72.
Renfrew, C., Dixon, J.E., Cann, J.R., 1968. Further analysis of Near East obsidian. Proc Prehist. Soc 34, 319-331.

Russo, R.E., Mao, X., Liu, H., Gonzalez, J., Mao, S.S., 2002. Laser ablation in analytical chemistry - a review. Talanta $57,425-451$.

Shackley, M.S. (Ed.), 1998. Archaeological obsidian studies, Method and theory. Advances in Archaeological and Museum Science 3. Plenum Press, New York and London, p. 243.

Shackley, M.S., 2011. An introduction to X-ray fluorescence (XRF) analysis in archaeology. In: Shackley, M.S. (Ed.), X-Ray Fluorescence Spectrometry (XRF) in Geoarchaeology. Springer, New York, pp. 7-44.

Sheppard, P.J., Irwin, G.J., Lin, S.C., McCaffrey, C.P., 2011. Characterization of New Zealand obsidian using PXRF. J. Archaeol. Sci. 38, 45-56.

Smith, M.E., Burke, A.L., Hare, T.S., Glascock, M.D., 2007. Sources of Imported Obsidian at Postclassic Sites in the Yautepec Valley, Morelos: A Characterization Study Using XRF and INAA. Lat. Am. Antiq. 18, 429-450.

Speakman, R.J., Neff, H., 2005. The application of laser ablation ICP-MS to the study of archaeological materials - an introduction. In: Speakman, R.J., Neff, H. (Eds.), Laser Ablation-ICP-MS in Archaeological Research. University of New Mexico Press, Albuquerque, pp. 1-14.

Speakman, R.J., Shackley, M.S., 2013. Silo science and portable XRF in archaeology: a response to Frahm. J. Archaeol. Sci. 40, 1435-1443.

Tykot, R.H., 1995. Prehistoric Trade in the Western Mediterranean: The Sources and Distribution of Sardinian Obsidian, Unpublished Ph.D. Dissertation. Department of Anthropology, Harvard University, Cambridge, Massachusetts.

Tykot, R.H., 1996. Obsidian procurement and distribution in the central and western Mediterranean. J. Mediterr. Archaeol. 9, 39-82.

Tykot, R.H., 1997. Characterization of the Monte Arci (Sardinia) Obsidian Sources. J. Archaeol. Sci. 24, 467-479.

Tykot, R.H., Ammerman, A.J., 1997. New directions in central Mediterranean obsidian studies. Antiquity 71, 1000-1006.

Williams-Thorpe, O., 1995. Obsidian in the Mediterranean and the Near East: a provenancing Success Story. Archaeometry 37, 217-248.

Yi, Seonbok, Jwa, Yong-Joo, 21 January 2016. On the provenance of prehistoric obsidian artifacts in South Korea, Quat. Int. (ISSN: 1040-6182) 392, 37-43. http://dx.doi.org/10.1016/j.quaint.2015.08.012 (http://www.sciencedirect com/science/article/pii/S1040618215007715). 